\title{
Migración, trabajo y acumulación de capital. Hacia un enfoque comprehensivo de las migraciones en el capitalismo global
}

\author{
Migration, labor and accumulation of capital. \\ Toward a comprehensive approach \\ of migrations in global capitalism
}

Alejandro I. Canales*

ISSN IMPRESO 1870-7599 | ISSN RED CÓMPUTO 2448-7783 | 71-103

RECIBIDO: 11/07/2018 | ACEPTADO: 19/07/2018

\begin{abstract}
Resumen. Las migraciones configuran un doble proceso de transferencias económicas. Por un lado, son una forma de transferencia de fuerza de trabajo desde las comunidades de origen hacia las economías desarrolladas; por otro lado, las remesas y distintos bienes y servicios que envían los migrantes constituyen un flujo en sentido inverso que contribuye a la reproducción social de los inmigrantes, sus familias y comunidades de origen. Este sistema de transferencias económicas vincula la reproducción de la fuerza de trabajo migrante en los lugares de origen, con la reproducción del capital y la economía en las sociedades de destino, de esa manera contribuye así, a la reproducción del capitalismo como sistema económico y productivo global.
\end{abstract}

Palabras clave: migración, acumulación de capital, trabajo, reproducción de la fuerza de trabajo, remesas.

\begin{abstract}
Migrations are a double process of economic transfers. On the one hand, they are a transfer of labor from the communities of origin to the developed economies. On the other hand, remittances and other goods and services that send migrants constitute a reverse transfer contributing to the social reproduction of immigrants, their families and communities. This double system of economic transfers links the reproduction of the migrant labor force in the places of origin with the reproduction of capital and economy in the destination societies, thus contributing to the reproduction of capitalism as a global economic and productive system.
\end{abstract}

Keywords: migration, accumulation of capital, labor, reproduction of wage-laborers, remittances.

\footnotetext{
${ }^{*}$ Chileno. Economista, demógrafo y doctor en Ciencias Sociales por El Colegio de México; profesor investigador en la Universidad de Guadalajara. Correo-e: acanales60@gmail.com
} 


\section{Introducción}

Desde la economía política, podemos entender las migraciones internacionales como un doble proceso de transferencias económicas que en conjunto contribuyen a la reproducción del sistema económico global. Por un lado, constituyen un proceso de transferencia de fuerza de trabajo desde las comunidades de origen hacia las economías desarrolladas. Aquí importa en términos de fuerza de trabajo cuyas aportaciones se manifiestan tanto en la dinámica del mercado laboral de las sociedades avanzadas, como en la producción y el crecimiento económico, por lo que coadyuva a la generación de los excedentes económicos necesarios para sustentar la reproducción ampliada del capital.

Por otro lado, y como contrapartida de la migración de fuerza de trabajo, se produce un flujo en sentido inverso que corresponde a las remesas que envían los migrantes a sus familias, las cuales representan un sistema de transferencias salariales que conforman la base de la reproducción social de los inmigrantes, sus familias y comunidades de origen. Así, las remesas son un fondo salarial, su función es la de reproducir la fuerza de trabajo necesaria y disponible para el capital y su acumulación (reproducción ampliada).

A través del flujo de migrantes laborales en un sentido, y de las remesas en sentido opuesto, se asocian las condiciones sociales y económicas de la reproducción social de la fuerza de trabajo en los lugares de origen con la acumulación de capital y el crecimiento y desarrollo económico en las sociedades de destino. Para entender esta idea sobre el papel de la migración laboral y de las remesas en la economía global, se retomarán algunos elementos analíticos y conceptuales de la teoría económica neoclásica así como visiones estructuralistas y marxistas.

\section{Del flujo circular de la renta a la reproducción del capital}

En todo manual de introducción a la economía se plantea que ésta funciona como un sistema, en el que cada transacción implica siempre un doble flujo: a) el que vende entrega un producto o servicio que tiene cierto valor de uso (utilidad) para el comprador; a cambio recibe en determinada forma de dinero lo que corresponde al valor de cambio del producto o servicio que ha vendido, y que se estima como el costo de producción del mismo. b) En el caso del comprador sucede lo contrario, entrega dinero a cambio de un producto que considera tiene alguna utilidad para 
él. De modo que el vendedor enajena un valor de uso, por el que recibe el valor de cambio de ese bien o servicio; a la vez que el comprador hace exactamente lo opuesto.

A partir de este principio la teoría económica plantea que el funcionamiento de la economía es como un sistema de circulación en dos direcciones. La circulación o flujo de lo material (bienes y servicios); y el flujo o circulación del dinero (ingresos, rentas, etcétera). Dicho modelo se denomina flujo circular de la renta o bien flujo circular de la actividad macroeconómica (Samuelson y Nordhaus, 2005). La mirada conjunta de ambos flujos permite entender el funcionamiento de la economía. Observemos ello con base en el modelo más sencillo que corresponde al intercambio económico entre dos agentes: las unidades domésticas y las unidades productivas.

Las unidades domésticas son familias o personas que participan de dos modos en el sistema económico: son los propietarios de los factores de producción (capital, tierra y fuerza de trabajo); y demandan bienes y servicios con la finalidad de satisfacer sus múltiples necesidades. Referente a las empresas son unidades que mediante estos factores productivos, generan bienes y servicios que ofrecen a las familias para su subsistencia y manutención. De esa manera, mediante el mercado de factores de producción, las familias venden factores y obtienen el ingreso indispensable para acceder al mercado de bienes y servicios y comprar aquellos que mejor satisfagan sus necesidades. Dichas empresas, con su capital inicial, compran los factores de producción (insumos, tecnología, etcétera) básicos para la producción de bienes, además pagan por ellos salarios, rentas y ganancias, conforme el factor productivo que estén comprando. Con tales factores de producción regresan al proceso de producción para la fabricación de bienes y servicios, los cuales posteriormente ofertarán en el mercado correspondiente y recuperarán la inversión inicial.

Este modelo se vuelve complejo al agregar nuevos agentes, mercados y componentes del sistema económico (Estado, empresas, consumidores del exterior, intercambios entre empresas, producción y circulación de insumos, bienes de capital y tecnología) según los distintos sectores de producción (primario, secundario, terciario o cualquier otra clasificación que surja en cada momento). Asimismo, desde visiones estructuralistas, las unidades domésticas suelen desagregarse en función de la propiedad de los factores de producción, hasta contar con un modelo aproximado de la estructura de clases y, por ende, de la distribución del ingreso (Castro y Lessa, 1991). Lo relevante es que opera el mismo principio 
de la circulación del ingreso, que va adquiriendo diversas formas según sean los actores de que se trate: salarios, rentas, utilidades y ganancias, impuestos, subsidios.

Con fundamento en ese modelo básico de funcionamiento de la economía se pueden ilustrar los elementos esenciales de la teoría macroeconómica, en específico, el origen y composición de la demanda agregada; el funcionamiento y rol del dinero, los mercados financieros, el sistema de ahorro-inversión, el comercio exterior (exportaciones-importaciones); las condiciones para ilustrar y entender las diferentes funciones del Estado en la economía, entre otros tantos aspectos.

Si bien desde la teoría económica neoclásica, el modelo es usado con el objetivo de analizar el flujo de la renta, y por ese medio, las condiciones para el crecimiento de la actividad económica así como su distribución entre los distintos agentes económicos, a partir de una perspectiva estructuralista es posible emplear ese modelo pero con el propósito de vincular los procesos de consumo (reproducción de la fuerza de trabajo) y de producción (reproducción del capital) (Balibar, 2004). Siguiendo el mismo esquema del flujo circular de la renta, puede entenderse el funcionamiento de la economía como la complementación de estos dos momentos.

Momento productivo. Corresponde a la producción de los medios de producción y medios de consumo intermedio (maquinarias, insumos, materias primas, tecnología); y la producción de los bienes y servicios de consumo final. En ese proceso, el capital consume la fuerza de trabajo, es decir, extrae de ella lo que tiene valor para el capital: el trabajo, en su doble carácter. Primero, como mano de obra concreta (su valor de uso), esto es, la capacidad del trabajador para utilizar otros medios de producción, insumos, tecnología, materias primas en la producción de bienes y servicios. Posteriormente, como trabajo abstracto (productor de valor), esto es, tiempo de trabajo abstracto (unidad básica de valor) que se transfiere a las mercancías en el proceso de trabajo y, por ese medio, hacer posible valorar el capital. En esta última capacidad, el trabajo se convierte en «un medio para crear riqueza en general, y ha dejado de estar vinculado como un atributo para un individuo en particular» (Marx, 1971:210).

Momento reproductivo. Se relaciona con el proceso de consumo individual (y familiar) de los bienes y servicios producidos previamente. A través del mencionado proceso las personas no sólo satisfacen sus necesidades (perspectiva neoclásica), sino que se reproducen a sí mismas y por ese medio, reproducen de modo cotidiano su propia fuerza de trabajo (perspectiva estructuralista); sin embargo, no se trata 
de una fuerza de trabajo para sí, sino para ser vendida a otros, en este caso, al capital. ${ }^{1}$ De manera que si para las personas dicho momento de consumo individual no representa un acto productivo propiamente tal, es decir, que les reditúe algo más que la satisfacción de sus necesidades, para el capital en cambio, constituye un momento productivo, pues corresponde a la producción y reproducción de la fuerza de trabajo, en otras palabras, del único componente del proceso de trabajo que tiene la capacidad de generar riqueza y valorizar al capital.

Aunque a primera vista parece ser el mismo esquema de la teoría económica, la visión estructuralista implica un giro adicional en términos de que no sólo da cuenta del proceso de acumulación del capital (crecimiento económico, ganancia, en lenguaje de la teoría neoclásica), sino que junto a ello, permite analizar la reproducción del capital en su forma material (dinero, bienes de producción, etcétera) y en su forma de relación social, en tanto relación que lo opone con la fuerza de trabajo. Bajo esta óptica, en cuanto al funcionamiento de la economía se habría logrado lo siguiente:

a) La producción de bienes y servicios de diverso tipo (medios de producción, insumos, materias primas, servicios productivos, bienes y servicios de consumo final). Corresponde a lo que en cuentas nacionales se documenta como actividad económica en sus diversas categorías y que se sintetizan en el valor de la producción, o sea el Producto Interno Bruto (PIB).

b) La reproducción de la fuerza de trabajo para el capital, esto es, de la capacidad de trabajo de las personas, la cual es ofrecida al capital para su uso (trabajo) a cambio de un salario.

${ }^{1}$ Esto es característico de una sociedad capitalista, en donde el trabajador es una persona «libre», esto es, que está en libertad de vender su fuerza de trabajo, en oposición a formas no capitalistas en donde el trabajador suele estar atado a la tierra, en el caso del sistema feudal o hacendal, o a sus amos, en el caso de formas esclavistas. Aunque en el capitalismo el trabajador ha logrado su libertad, el problema es que al no ser propietario de nada más que de su fuerza de trabajo, esa libertad es en realidad una restricción, un condicionamiento estructural a tener que vender su fuerza de trabajo para conseguir los recursos necesarios para su manutención y reproducción. En tal sentido, en el capitalismo el momento del consumo es en realidad un campo de reproducción de fuerza de trabajo no para sí mismos, sino para otros, para el capital (Marx, 1972; Balibar, 2004). Desde una perspectiva diferente, pero complementaria, Polanyi (2017) señala que la fundación del capitalismo se sustenta, entre otros factores, en la conformación del mercado de trabajo, esto es, la constitución del trabajo como una mercancía y del trabajador como un asalariado. El problema es que el trabajo y la fuerza de trabajo, aun cuando puedan transarse en el mercado por un precio, en realidad ello representa un acto ficticio, pues el trabajo es en sí mismo una actividad humana que no puede des-incrustarse de todas sus dimensiones culturales, sociales, familiares, políticas y humanas, que la constituyen. Sólo a través de un acto de imposición y de poder fue posible crear esta ficción del trabajo como mercancía en sí misma. 
c) La reproducción del capital en forma ampliada, que no es sino el leit motiv del capitalismo, lo que impulsa al capitalista a re-iniciar una y otra vez todo ese circuito de producción y valorización del capital.

Finalmente, reproducción de la relación social entre capital y trabajo, como entidades económicas opuestas pero que son la base del funcionamiento del sistema económico, mismo que reinicia constantemente el proceso económico de trabajo y la valorización del capital (acumulación), es un proceso ad infinitum.

Ahora bien, este es un modelo general que describe el funcionamiento de la economía capitalista en abstracto. Lo que nos interesa es reconstruirlo para el análisis y el entendimiento del papel de la migración contemporánea en el proceso de reproducción de capital, y ello a su vez en el actual contexto de globalización económica. En específico, pretendemos ilustrar cómo en dicho contexto de globalización, la migración internacional constituye un mecanismo que permite la vinculación entre los momentos productivos (de valorización del capital) en los países de destino, con los momentos reproductivos de la fuerza de trabajo en los países de origen de las migraciones y, por ese medio, contribuye a vincular la reproducción del capital con la reproducción de la fuerza de trabajo. En la figura 1 mostramos esta tesis: a través de la migración internacional se asocia a un mismo proceso de globalización la reproducción de la fuerza de trabajo migrante con la reproducción del capital.

FIGURA 1

Migración laboral y reproducción del capital

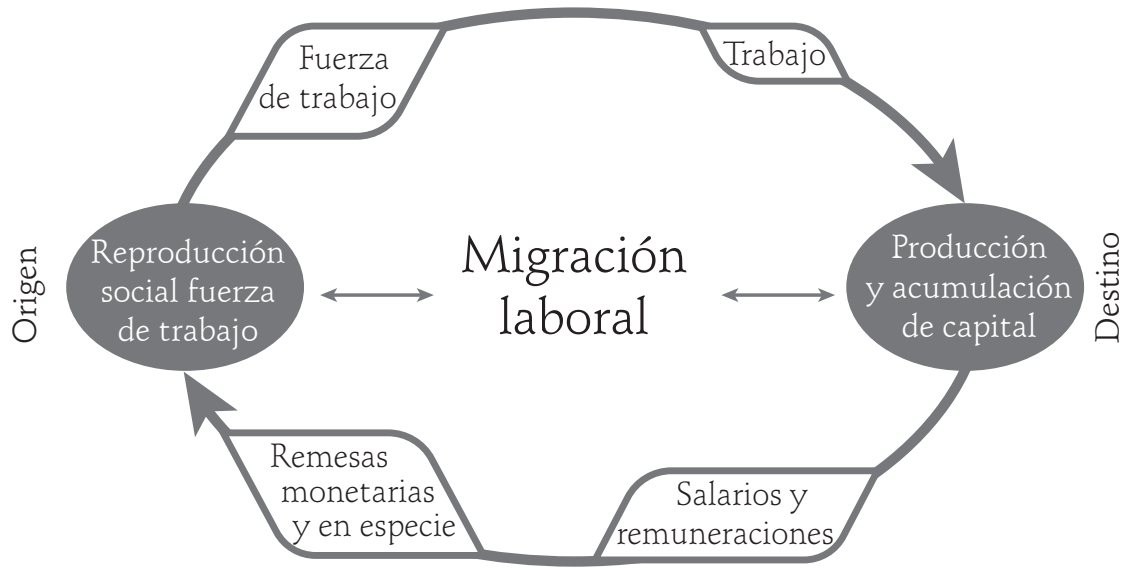


Las migraciones son un proceso doble de transferencias económicas: en principio, se trata de una transferencia de trabajo de las comunidades de origen a las economías desarrolladas; en seguida, las remesas y otros bienes y servicios enviados por los migrantes constituyen una transferencia inversa que contribuye a la reproducción social de los inmigrantes, sus familias y las comunidades. Este doble sistema de transferencias financieras vincula la reproducción de la mano de obra migrante en los lugares de origen con la reproducción del capital en las sociedades de destino, de modo que contribuye a la reproducción del capitalismo como un sistema económico y productivo global.

El aludido vínculo entre los momentos productivos y reproductivos es posible examinarlo desde el papel de la migración en la configuración de los mercados laborales en la economía global. Se menciona a los mercados globales de fuerza de trabajo en los que el vínculo espacial entre el momento reproductivo de la fuerza de trabajo y el momento productivo del capital se da (aunque no exclusivamente) mediante la migración y los procesos sociales y económicos que se activan en su desarrollo y continuo devenir. Esta configuración territorial permite que la reproducción de la fuerza de trabajo y del capital se desarrollen en espacios y lugares diversos y distantes entre sí, sin mayor relación que la generada por la propia migración de la fuerza de trabajo.

Con la globalización, el capital ha logrado reubicar los momentos reproductivos de la fuerza de trabajo más allá de las fronteras nacionales, y por esa razón ha posibilitado la separación de la reproducción social de la fuerza de trabajo de todo el sistema social y político, algo que en el fordismo y el capitalismo industrial se integraba a través del Estado, la política y las instituciones más diversas que estructuraron las sociedades capitalistas del mundo desarrollado a lo largo del siglo $X X$. Sin embargo, esta desconexión entre los dos momentos de acumulación de capital es sólo aparente y oculta la verdadera función de la migración laboral como un dispositivo articulador de ambos momentos que sostienen la acumulación de capital en la economía global. A continuación se describen y explican dichos vínculos de la migración con la reproducción del sistema económico global.

\section{Migración laboral y reproducción del capital}

En torno del llamado momento productivo, ciertos autores resaltan los cambios en su configuración espacial en las últimas décadas, a partir del advenimiento 
de la economía global. Sin entrar en los pormenores del debate acerca de la globalización, es importante centrar la atención en el análisis de las transformaciones que la globalización ha introducido en las formas organizativas del trabajo y las relaciones laborales, en la medida que ello configura el contexto de la inserción laboral de los inmigrantes en la economía global.

Tales cambios en la estructura y dinámica del empleo y del mercado de trabajo se sustentan en los nuevos paradigmas productivos y organizacionales de la globalización. Nos referimos al postfordismo, la producción just in time, la idea de una fábrica global, la desregulación económica de los mercados y el fin del Estado de bienestar, la flexibilidad laboral y segmentación de los mercados de trabajo, entre muchos otros aspectos (Mendieta, 2007; Hirst y Zeitlin, 1991; Amin, 2000; Koch, 2017).

Así se configuran mecanismos de inclusión/exclusión social que, a través de la precarización del empleo y otras formas modernas de segregación social, afectan preferentemente a sectores sociales debilitados ante la desregulación económica y la flexibilidad laboral, como lo son en este caso los trabajadores migrantes en los países desarrollados (Sassen, 1998). Los procesos de globalización no son bajo ninguna circunstancia geográficamente uniformes, sino heterogéneos y diferenciados, con base en los cuales se crean y recrean distintas formas de desigualdad social, económica y espacial (Stiglitz, 2012). Estas formas de diferenciación y desigualdad social se sustentan en nuevas formas de estratificación social de la población que tiene bases económicas y demográficas que vale la pena retomar. Si consideramos que el proceso social de trabajo es la base de la estructura social, entonces, es de esperar que los cambios a este nivel reflejen y repercutan directamente en la estructuración de la sociedad en clases, estratos y grupos sociales diferenciados. En ese sentido, es oportuno referirse a las transformaciones en la estructura social del empleo y las ocupaciones y, en general, de las relaciones capital-trabajo.

Al respecto, algunos autores indican que con la globalización económica, la dinámica del mercado laboral se involucra en dos procesos que se complemen$\tan$ y refuerzan mutuamente. Por un lado, las transformaciones en la matriz laboral y en la estructura económico-productiva; por otro lado, la polarización de las ocupaciones y la segmentación de los mercados laborales (Koch, 2017; Amin, 2000). 


\section{Desindustrialización y terciarización en la nueva matriz laboral}

Acerca de los cambios en la estructura del empleo existe un amplio debate entre las diversas teorías sobre la sociedad postindustrial. Inicialmente, autores como Daniel Bell (1973) enfatizaron el nacimiento de una nueva estructura social sustentada en el tránsito de una economía industrial a una de servicios productivos $y$, por ende, en el auge de las ocupaciones ejecutivas y profesionales, aunado a la desaparición no sólo de los trabajos agrícolas y primario-extractivos, sino también y de modo decisivo, los del sector industrial. Otros como Manuel Castells (1998) indican que el carácter postindustrial de las sociedades contemporáneas no se expresa en el declive de las actividades industriales o en el nuevo carácter que poseen. El énfasis se coloca en el cada vez mayor contenido de información y conocimiento que requiere el proceso de trabajo y que repercute en la estructura de ocupaciones y empleo. En ese sentido, Castells opta por hablar de sociedad informacional, y no tanto por sociedad postindustrial. Es evidente, entonces, el hecho de que la producción industrial se apoya en un proceso de intercambio y procesamiento de información, más que de intercambio y procesamiento de materiales.

Scott Lash y John Urry (1998) van más allá y plantean que el carácter informacional de la nueva economía se soporta en la reconfiguración de los procesos de trabajo a partir de procesos de reflexividad del trabajo, lo que conlleva distintos modos de autorregulación que transforman el proceso de trabajo en objeto de sí mismo, y no sólo en un medio de transformación de materiales y objetos externos. Consideran que los conceptos de flexibilidad, desregulación, postfordismo y otros similares son inadecuados, pues cargan con un sesgo productivista que no les permite entender que ese proceso de producción y trabajo se sostiene en un saber discursivo y reflexivo por sí mismo.

Dichos procesos impulsan transformaciones en la dinámica económica y matriz productiva de las sociedades actuales. Nos referimos al proceso de desindustrialización y terciarización de la economía de los países desarrollados, los cuales además de sustentarse en la relocalización de capitales y procesos productivos desde las economías centrales hacia otras regiones del mundo, aprovechan las ventajas que ofrecen en cuanto a valor de la fuerza de trabajo, exenciones tributarias, flexibilidad en políticas ambientales, infraestructura de comunicaciones y transporte, entre otros (Castillo y Sotelo, 2013; Cypher y Delgado 2010).

Al respecto, los datos para Europa y Estados Unidos son elocuentes. Entre 1998 y 2018 el empleo en Estados Unidos creció, en términos netos, en 23 millones 
de puestos de trabajo. No obstante, este crecimiento no se distribuye por igual en todos los sectores económicos, sino que se concentra en determinadas actividades a la vez que deja a otras en un virtual estancamiento y retroceso productivo. En el primer caso se sitúan los servicios personales, sociales, financieros y profesionales, en el que el empleo creció en conjunto en 33.6 millones de nuevos puestos de trabajo. En el segundo caso se ubican la industria manufacturera y el comercio, actividades donde el nivel de empleo se redujo en conjunto en 13.1 millones de puestos de trabajo (cuadro 1).

Referente a Europa sucede algo parecido. En el citado periodo el empleo creció 22.6 millones de nuevos puestos de trabajo; aunque al igual que en Estados Unidos, este crecimiento se concentró en los sectores de servicios sociales que incrementó 14 millones, seguido de los servicios a empresas y servicios personales que aumentaron 8.3 y 7.7 millones de empleos, respectivamente. Por el contrario, el empleo en los sectores directamente productivos decreció de manera notable. En la agricultura, ganadería y pesca el descenso fue de casi 3.2 millones de puestos de trabajo, caída que alcanza los 6.7 millones en el caso de la industria manufacturera.

Esta diferente dinámica del empleo por sectores de actividad refleja una transformación no menor de la matriz laboral de las economías centrales. Tanto en Europa como en Estados Unidos en los 1990 el comercio y los servicios sociales contribuían en casi partes iguales con 50 por ciento del empleo, a la vez que la industria manufacturera aportaba 17 por ciento en Estados Unidos y 21 por ciento en Europa. En cuanto a los servicios a empresas (financieros y profesionales) aportaban 17 por ciento del empleo en Estados Unidos, y sólo 11 por ciento en Europa (cuadro 1).

En la actualidad, esa composición se ha modificado de modo considerable. Los servicios sociales son por lejos el principal sector de empleo con una aportación de 30 por ciento de las ocupaciones en Estados Unidos y 33 por ciento en Europa. Asimismo, mientras los servicios profesionales y financieros incrementan participación en 4 puntos porcentuales, la industria manufacturera la reduce en casi 7 puntos porcentuales en Europa y en Estados Unidos. La contraposición de ambas dinámicas es expresión de la nueva orientación de la economía de los países centrales, donde la producción directa de mercancías tiende a ser sustituida por la generación de servicios a la producción, derivado de la configuración de una economía de la información y la consolidación de los procesos de reflexividad en la organización de los procesos de trabajo que ya se comentó (David y Foray, 2002). 


\section{CUADRO 1}

Estados Unidos y Unión Europea (15 países) 1998 y 2018. Empleo según sector de actividad económica (miles de trabajadores)

\begin{tabular}{|c|c|c|c|c|c|c|c|c|}
\hline & \multicolumn{4}{|c|}{ Estados Unidos } & \multicolumn{4}{|c|}{ Unión Europea (15 países) } \\
\hline & \multicolumn{2}{|c|}{$\begin{array}{l}\text { Volumen de empleo } \\
\text { (miles) }\end{array}$} & \multicolumn{2}{|c|}{$\begin{array}{c}\text { Distribución } \\
\%\end{array}$} & \multicolumn{2}{|c|}{$\begin{array}{c}\text { Volumen de empleo } \\
\text { (miles) }\end{array}$} & \multicolumn{2}{|c|}{$\begin{array}{c}\text { Distribución } \\
\%\end{array}$} \\
\hline & 1998 & 2018 & 1998 & 2018 & 1998 & 2018 & 1998 & 2018 \\
\hline Total & 129561 & 152597 & 100 & 100 & 152662 & 175274 & 100 & 100 \\
\hline Agricultura & 2206 & 2352 & 2 & 2 & 7700.2 & 4543.5 & 5 & 3 \\
\hline Construcción & 8134 & 10609 & 6 & 7 & 11794.7 & 11429.6 & 8 & 7 \\
\hline Manufacturas & 22627 & 16931 & 17 & 11 & 31712.5 & 25011.5 & 21 & 14 \\
\hline Comercio & 33074 & 25596 & 26 & 17 & 33114.1 & 35895.1 & 22 & 20 \\
\hline $\begin{array}{l}\text { Servicios } \\
\text { profesionales } \\
\text { y financieros }\end{array}$ & 21764 & 32254 & 17 & 21 & 17303.4 & 25668.2 & 11 & 15 \\
\hline Servicios sociales & 30931 & 45184 & 24 & 30 & 43348.6 & 57345.4 & 28 & 33 \\
\hline $\begin{array}{l}\text { Servicios } \\
\text { profesionales }\end{array}$ & 10823 & 19671 & 8 & 13 & 7688.4 & 15380.7 & 5 & 9 \\
\hline
\end{tabular}

Fuente: Current Population Survey, march supplement, 1998 y 2018; European Comission, s/f.

Destaca también el gran incremento de los trabajos en los servicios personales (doméstico, cuidado de personas, preparación de alimentos, limpieza y mantenimiento, entre otros). Se trata de empleos de baja calificación y alta precariedad laboral donde suelen insertarse trabajadores inmersos en diversas condiciones de vulnerabilidad social. En Europa y en Estados Unidos estas actividades elevan su participación en algo más de 4 puntos porcentuales, con ello reflejan las tendencias a la polarización y segmentación de los mercados de trabajo (Canales, 2017).

Bajo ese contexto, es pertinente analizar los patrones de inserción laboral de los trabajadores migrantes, quienes por su condición de vulnerabilidad acostumbran incorporarse en los empleos menos protegidos y con mayores grados de flexibilidad laboral. En el caso de Estados Unidos, los datos ilustran dicha tesis. En 2018 los inmigrantes provenientes de países del tercer mundo tienden a insertarse preferencialmente en aquellos sectores manufactureros y productivos que han quedado desfasados en el proceso de acumulación capitalista global o bien en los servicios de menores niveles de cualificación. Se trata de actividades 
con menor capacidad de generar valor agregado, menores niveles de productividad y mayor flexibilidad laboral. Así, los inmigrantes del tercer mundo ocupan 20 por ciento de los empleos agropecuarios y 26 por ciento de los trabajos de la construcción. Se trata de trabajos altamente precarios y flexibles en los que predomina la contratación por tiempo definido y jornaleros diarios (figura 2).

\section{FIGURA 2}

Participación de inmigrantes del tercer mundo según sectores de actividad, Estados Unidos, 2018
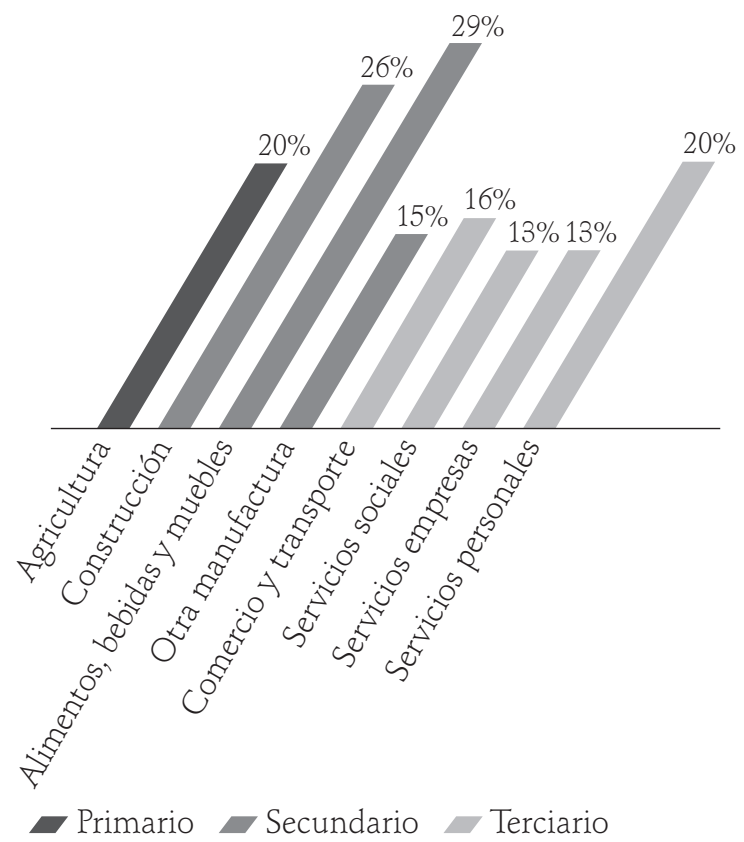

Concerniente al proceso de desindustrialización, determinadas ramas de las más afectadas se reorientan hacia la contratación de trabajadores migrantes, tal es el caso de la industria textil y del calzado, la de alimentos, bebidas y tabaco, así como la de producción de muebles. En conjunto en todas ellas los trabajadores migrantes del tercer mundo representan 29 por ciento de la ocupación en esas ramas industriales. Por el contrario, en aquellas ramas industriales con mejor posición competitiva y desarrollo tecnológico, como lo son la industria microelectrónica, automotriz, maquinaria y equipo, metal mecánica, y similares, la contratación de inmigrantes se reduce a 15 por ciento del total. 
Los inmigrantes tienden a quedar relegados a aquellas actividades y servicios más rezagados y que se encuentran muy distantes de constituir la base de la economía del conocimiento y la información. En concreto, los inmigrantes del tercer mundo sólo representan 13 por ciento del empleo en los servicios propios de la era de la información (profesionales, servicios financieros, servicios a empresas, entre otros); al igual que en los servicios sociales (salud, educación, gobierno). A pesar de lo anterior, estos inmigrantes contribuyen con 20 por ciento del empleo en los servicios personales y del cuidado, es decir, servicios con bajos niveles de calificación laboral y, en consecuencia, con altos niveles de precariedad laboral y desregulación contractual.

\section{Migración y déficit laboral}

Las aludidas condiciones económicas de polarización al igual que las deficiencias demográficas que caracterizan a los países desarrollados, configuran el marco estructural que nos permite entender la función de la migración en la dinámica económica de esos países. En primer lugar, el cambio demográfico iniciado en las últimas décadas se manifiesta crecientemente en un déficit persistente de mano de obra local. El envejecimiento de la población y el descenso de la fecundidad en el marco de la segunda transición demográfica, conllevan no sólo a un lento y a veces nulo crecimiento demográfico, sino a un cambio sustancial en la estructura etaria de la misma, lo que se refleja en un incremento de la población en edades adultas y en una reducción de edades jóvenes. Dicho cambio demográfico ya está afectando la capacidad de las sociedades avanzadas para proveerse internamente de la población activa indispensable capaz de mantener los ritmos de crecimiento económico y transformación productiva. Se trata además de economías que requieren generar los excedentes mínimos con la finalidad de mantener no sólo sus altos niveles de vida y patrones de consumo suntuosos, sino para conservar y reproducir cotidianamente una amplia clase ociosa (según Veblen), en especial en términos de una industria de guerra y de un ejército de administración de la economía y la política internacional, que les posibilite sostener su privilegiada posición dominante y hegemónica en la sociedad mundial.

El aumento económico de los países centrales, aunado a su imperiosa necesidad de generación y acumulación de excedentes que garanticen su posición de primacía económica y política a escala mundial, siempre ha implicado una gran 
demanda de mano de obra. Expresión de ello es el auge económico y social de la posguerra. Hasta los 1970 esa demanda pudo satisfacerse de modo interno a partir de la dinámica demográfica de la población de tales países. En concreto, el baby boom de la posguerra contribuyó a proveer de esa población en edades activas, lo que redujo las necesidades de su importación desde países periféricos bajo la forma de inmigrantes.

En la década de 1980, cuando los efectos directos e indirectos del baby boom llegan a su fin, la creciente demanda de población activa se resuelve a través de dos fenómenos complementarios: la relocalización de parte del aparato productivo e industrial desde las economías centrales hacia las periféricas, y la importación directa de mano de obra bajo la forma de inmigración desde países periféricos. Este contexto posibilita entender la forma, magnitud, perfiles y tendencias de la migración contemporánea hacia los países centrales. En otra palabras, la demografía en las sociedades avanzadas muestra una evidente insuficiencia estructural que propicie los contingentes de trabajadores que ocupen los puestos laborales que la dinámica y el crecimiento económico genera cotidianamente. Frente a ese desajuste estructural entre la dinámica demográfica interna y la dinámica económica, la solución ha sido apelar a la inmigración masiva de trabajadores, provenientes en su mayoría de países del tercer mundo, donde se vive un régimen demográfico distinto.

Desde 1990 se constata un persistente y creciente desequilibrio entre la oferta de puestos de trabajo que desencadena el crecimiento económico, y que demanda por tanto, la reproducción del capital y la oferta de mano de obra que la demografía local se encuentra en condiciones de generar (Canales, 2018). Ese déficit se mantiene hasta nuestros días, incluso a pesar de los efectos negativos de la crisis económica en la generación y crecimiento del empleo en las economías centrales. Con respecto a España, entre 2000 y 2018 la economía creó 3.33 millones de nuevos empleos, no obstante el serio impacto de la crisis de los últimos años, que implicó una pérdida de casi 3.8 millones de puestos de trabajo entre 2008 y 2013. En contraste, la dinámica demográfica de la población española (sin los inmigrantes), generó tan sólo 1.56 millones de nuevos trabajadores, lo que implica un déficit de mano de obra que alcanza los 1.77 millones de personas (figura 3). Lo anterior significa que la economía española aun en un contexto de lento crecimiento del empleo derivado de la crisis económica actual, provoca un incremento en la oferta de empleo que es 2.1 veces superior a la capacidad de crecimiento demográfico de su población activa. 
En el caso de Estados Unidos la situación es muy similar. Si bien en el mismo periodo la dinámica de crecimiento de su economía generó 20.3 millones de nuevos empleos, entre 2007 y 2010 perdió 7.5 millones de empleos como consecuencia de la crisis económica. Con todo, la dinámica demográfica de su población nativa no latina apenas pudo generar una oferta de fuerza de trabajo de 3.7 millones de personas. En ese caso, el déficit de mano de obra supera en 5.5 veces la capacidad demográfica de su población nativa.

FIGURA 3

España y Estados Unidos, estimación del déficit laboral, 2000-2018 (millones de personas)

Crecimiento puestos de trabajo

Crecimiento fuerza de trabajo nativa

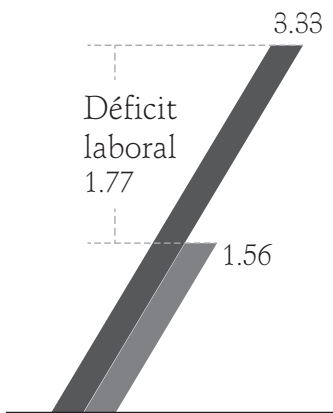

España

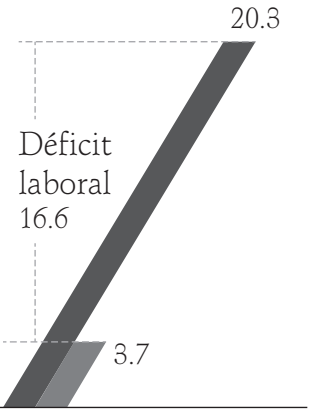

Estados Unidos

Fuente: INE, España, Encuesta de Población Activa, 2000-2018; US Bureau of Census, Current Population Survey, march supplement, 2000-2018.

Con base en lo anterior, la presente tesis sostiene que en los países avanzados la inmigración desde países periféricos contribuye a llenar el vacío demográfico ocasionado por la insuficiencia estructural de sus actuales patrones de reproducción demográfica, manifiesta en un déficit crónico de población económicamente activa. En este marco, podemos comprender el papel de la inmigración laboral a esos países para contrarrestar los efectos que el envejecimiento de la población nativa está teniendo sobre su dinámica económica.

Concerniente a España, entre 2000 y 2018, la inmigración latinoamericana cubrió 30 por ciento de déficit laboral que deja el lento crecimiento de la fuerza de trabajo nativa en ese país; mientras que en Estados Unidos fue de 35 por 
ciento, cantidad a la que debe agregarse 30 por ciento de las aportaciones de hijos y descendientes (Canales, 2018). Si en términos demográficos la migración laboral contribuye a paliar el déficit de mano de obra, en términos económicos y productivos posee un significativo impacto para mantener y potenciar la dinámica económica y, de ese modo, favorecer la reproducción y acumulación de capital. Al respecto, los datos resultan también ilustrativos, en términos de mostrar cómo la inmigración contribuye cada vez más a la generación del Producto Interno Bruto (PIB) y a la acumulación de capital en las sociedades avanzadas.

\section{CUADRO 2}

Volumen y crecimiento del producto interno bruto según origen étnico de la fuerza de trabajo. Estados Unidos, 2000 y 2018

\begin{tabular}{lcc|cc} 
& \multicolumn{2}{c|}{$\begin{array}{c}\text { PIB (miles de millones de } \\
\text { dólares a precios de 2012) }\end{array}$} & \multicolumn{2}{c}{$\begin{array}{c}\text { Crecimiento del PIB } \\
\text { 2000-2018 }\end{array}$} \\
\cline { 3 - 4 } & 2000 & 2018 & Volumen & Distribución \% \\
\hline PIB total & 13569 & 18407 & 4838 & 100.0 \\
Blancos no latinos & 9778 & 11536 & 1757 & 36.3 \\
Otros no latinos & 1637 & 2435 & 798 & 16.5 \\
Latinos nacidos en EUA & 512 & 1208 & 696 & 14.4 \\
Inmigrantes latinos & 705 & 1423 & 718 & 14.8 \\
Otros inmigrantes & 937 & 1806 & 869 & 18.0 \\
\hline
\end{tabular}

Fuente: estimaciones propias con base en US Bureau of Census, Current Population Survey, 2000 y 2018; US Bureau of Economic Analysis, 2018.

Para el mismo periodo 2000 y 2018, el PIB en Estados Unidos creció 4.8 mil millones de dólares (36 por ciento acumulado para todo el periodo), pero sólo 36.3 por ciento de este crecimiento fue proporcionado por la mano de obra blanca no latina, no obstante representa 61 por ciento del empleo total (cuadro 2). En cambio, aunque los latinos (inmigrantes y nativos) contribuyeron con 29 por ciento del crecimiento del PIB representan 16 por ciento de la población ocupada en 2018. Asimismo, los inmigrantes provenientes de otras regiones del mundo generaron 18 por ciento del crecimiento económico, aun cuando sólo representan 10 por ciento de la población ocupada. Dicho aporte al crecimiento económico puede entenderse como una estimación del grado de dependencia de las economías de las sociedades avanzadas con relación a la necesaria provisión de mano de obra inmigrante, ante la insuficiencia demográfica que ya se manifiesta en su población nativa. 
Los datos ilustran el grado de dependencia que adquieren las economías centrales respecto a la inmigración laboral para sostener el crecimiento económico y, por tanto, para la reproducción ampliada del capital. Por un lado, contribuyen directamente a cubrir el déficit de mano de obra que propicia su dinámica demográfica; por otro lado, suelen emplearse en sectores que aunque son de baja productividad, no dejan de ser relevantes e indispensables en la reproducción de la población, en especial de las clases medias y altas. Por último, contribuyen de manera fundamental para mantener la dinámica productiva y el crecimiento económico y del PIB, esencial para conservar su posición hegemónica y de dominio económico, político y militar a escala mundial.

\section{Transnacionalismo, redes sociales y remesas: la reproducción de la fuerza de trabajo}

Desde una perspectiva estructuralista, el precio de la fuerza de trabajo, es decir, el salario y las remuneraciones de los trabajadores, se determina de acuerdo con su costo de reproducción: gastos y recursos necesarios que permitan reproducir cotidiana e intergeneracionalmente al trabajador y su familia. En concreto, el salario debe cubrir las necesidades de reproducción social del trabajador y solventar sus gastos en consumo y alimentación diaria, salud, educación, vestido y calzado, vivienda, transporte, entre otros. Sin embargo, los costos de la reproducción de los trabajadores y sus familias (y de la población, en general) son cuantitativamente muy diferentes según se trate de los países de origen o de destino de la migración. Ello es especialmente válido en la actual oleada migratoria que se origina en los países subdesarrollados del Sur y que se dirige a las sociedades avanzadas del Norte.

En este contexto, el aporte de la migración laboral no significa sólo proveer fuerza de trabajo para el capital pura y simplemente, sino proveer mano de obra barata, a bajo costo salarial, así como en condiciones de vulnerabilidad y diferenciación social que la hagan susceptible de insertarse en puestos de trabajo caracterizados por su alta flexibilidad e inestabilidad laboral, baja calificación, precarios y mal pagados. Como una forma de mantener esta situación, a través de la provisión de mano de obra migrante, las economías centrales han podido trasladar gran parte de los costos de la reproducción de la fuerza de trabajo hacia las comunidades de origen de los migrantes en las economías periféricas. Se trata 
de un proceso de deslocalización de la reproducción de la fuerza de trabajo, de modo que en el caso de la población migrante, el costo de su reproducción social y mano de obra asalariada no está determinado necesariamente por las condiciones y estilos de vida que prevalecen en las sociedades de destino, sino que en gran medida dependen de las condiciones de vida que prevalecen en los lugares de origen, los cuales son sustancialmente más baratos y precarizados.

Con relación al gasto en salud por ejemplo, con base en datos del Banco Mundial estimamos que en los países latinoamericanos el gasto per cápita anual en salud es 6 veces inferior al que se da en los países europeos inscritos en la zona del euro junto al Reino Unido, y más de 12 veces inferior al de Estados Unidos. De igual modo, el gasto per cápita anual en educación primaria en los países latinoamericanos es 8 veces menor al de los países de la zona del euro y el Reino Unido, y más de 10 veces inferior al de Estados Unidos (Banco Mundial, 2019b). Lo anterior indica que el costo de reproducción de la fuerza de trabajo en los países de destino es muy superior al que prevalece en los países de origen. De ahí que la migración de la población en edades activas desde los países periféricos a las economías centrales, conlleve un proceso que va en contraflujo, y que podemos conceptualizarlo como una forma de transferencia de ese costo de reproducción desde las economías centrales hacia las economías periféricas, abaratándolo significativamente. En este proceso ocupan un lugar central el sistema de redes sociales y familiares sobre la que se sustenta la migración como proceso social.

La migración da lugar a un complejo sistema de redes sociales y familiares, que sustentadas en principios de solidaridad, confianza y reciprocidad, permiten la reproducción de los migrantes, así como de sus familias y comunidades, en lo que se ha denominado como un proceso de causación acumulativa (Massey, 1990). Diversos autores han planteado que la migración internacional constituiría una estrategia transnacional de reproducción social de los migrantes y sus familias (De Haas, 2007). A ello agregamos que las redes familiares y el capital social de los migrantes, aunado al hecho de convertirse en una estrategia de reproducción de la migración como proceso social, son también, y a través de ese mismo proceso, una forma de reproducción social de la fuerza de trabajo de los migrantes, es decir, un modo de reproducción de los migrantes como trabajadores transnacionales.

Es innegable que las redes y el capital social de los migrantes son el mecanismo mediante el cual se desarrolla y perpetua la migración (permite al migrante reducir costos y riesgos del desplazamiento, insertarse en los lugares de 
destino, conseguir empleo, y participar e integrarse a una comunidad de paisanos), adicionalmente, a través de ese mismo proceso y con fundamento en esas mismas redes sociales, se traslada a los propios migrantes, a sus familias y a sus comunidades gran parte del costo de la reproducción de esa fuerza de trabajo.

Desde una perspectiva sociológica y antropológica las redes sociales son parte de la reproducción de la familia y la migración como proceso social; desde la perspectiva de la economía política, entendemos que el aludido proceso constituye igualmente una parte esencial de la reproducción de la fuerza de trabajo migrante. Las redes sociales ponen en movimiento fuerza de trabajo al hacerla disponible para ser contratada por capitalistas y empresarios en los lugares de destino. Empero, esas mismas redes sociales dan sustento a la reproducción social (cotidiana y generacional) de esa fuerza de trabajo, al liberar capital y a las economías en los lugares de destino de parte del costo de dicha reproducción de la mano de obra. Los efectos favorables para el capital son evidentes: permiten una reducción de los salarios devengados, a la vez que contribuyen al aumento de los márgenes de ganancia del capital y, por ende, su capacidad de reproducción y acumulación, lo que fortalece su poder de competitividad a escala global.

El continuo flujo de bienes materiales y simbólicos que se da entre las comunidades de origen y de destino, constituye uno de los mecanismos por medio del cual se traspasa parte de los costos de reproducción de la fuerza de trabajo desde las economías centrales hacia las economías periféricas. Nada ejemplifica mejor esta situación que el flujo de remesas que los migrantes envían cotidianamente a sus familiares en las comunidades de origen y que en su mayoría son usadas para financiar el consumo de sus hogares. Así como en el actual mundo globalizado las migraciones representan un sistema de transferencia de fuerza de trabajo desde el tercer mundo hacia las economías del mundo desarrollado, las remesas encarnan un sistema de transferencias salariales no sólo en sentido inverso, sino consustancial a este proceso global que enmarca las migraciones internacionales en el presente.

En las últimas dos décadas las remesas mundiales prácticamente se han sextuplicado, pasando de 110 mil millones de dólares en la segunda mitad de los 1990, a 630 mil millones en 2017; se estima que en 2018 llegó hasta 690 mil (Banco Mundial, 2019a). Aunque en el momento de la crisis económica sufrieron un momentáneo freno y decrecimiento, su tendencia a largo plazo es de un crecimiento continuo y sistemático, lo que las constituye en uno de los flujos monetarios internacionales más estables y predecibles del capitalismo global. 
En todo caso, lo relevante es que las remesas constituyen un claro flujo Norte-Sur, donde el origen tiende a ser el de las economías centrales y su destino es hacia las economías periféricas. Conforme a datos del Banco Mundial, se considera que entre 2005 y 2018, prácticamente 80 por ciento de las remesas se originaron en las economías centrales y sólo 20 por ciento en países en vías de desarrollo (figura 4). En éstos se trata de países del golfo Pérsico que reciben importantes flujos migratorios atraídos por la industria petrolera; sin embargo, para esos mismos años los datos y estimaciones del Banco Mundial destacan que 76 por ciento de las remesas se dirigen hacia los países en vías de desarrollo, y únicamente 24 por ciento a los países centrales, ello indica el carácter y sentido Norte-Sur del flujo de remesas.

\section{FIGURA 4}

Composición de remesas mundiales según países de origen y de destino

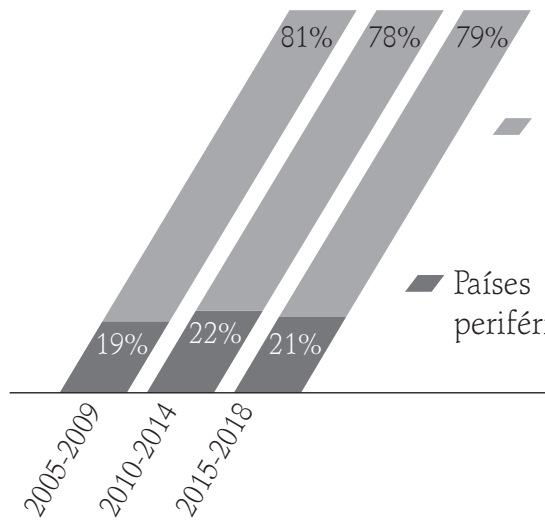

Remesas según país de origen

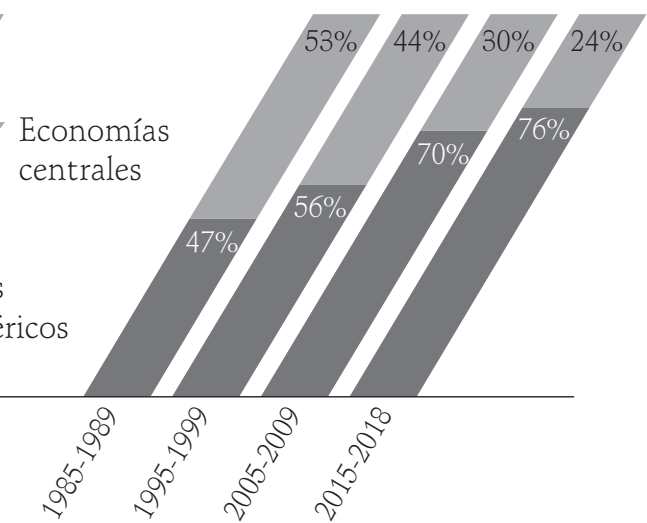

Remesas según país de destino

Fuente: Banco Mundial, 2019a.

De complementaria manera es preponderante constatar que esta composición de las remesas, según regiones de destino, no siempre ha sido la misma. Hasta la segunda mitad de la década de 1980, las economías centrales eran las principales receptoras de remesas, región hacia donde fluía más de 50 por ciento del total de las remesas mundiales. Es a partir de la década de 1990, cuando se expande y consolida el gran flujo migratorio desde países periféricos a las economías centrales, que esta relación se invierte, de modo que alcanza la distribución actual mencionada. En la figura 4 se aprecia crecientemente que las 
remesas constituyen y se consolidan como un flujo salarial proveniente de los países centrales hacia los países en vías de desarrollo, en contrapartida del flujo Sur-Norte que caracteriza a las migraciones contemporáneas.

Esta reorientación de los flujos de remesas junto a su gran estabilidad indica la relevancia que tienen para los migrantes y sus familias perceptoras. Incluso en contextos de crisis económica, pérdida de empleos, inestabilidad laboral y deterioro de las condiciones de vida de los migrantes en los lugares de destino, el flujo nunca se desplomó, siempre mantuvo niveles muy estables y superiores a otros flujos monetarios internacionales que perciben los países en vías de desarrollo.

Las remesas son una fracción de los salarios y remuneraciones que perciben los migrantes laborales, la cual posee la misma función económica que cualquier otro salario: reproducción de fuerza de trabajo. En ese sentido, las remesas son la forma en que una fracción del salario del migrante se transfiere a sus familias y comunidades de origen para la reproducción social de la familia y la comunidad, al igual que lo haría cualquier otro ingreso salarial en esas comunidades.

Las remesas no sólo forman parte del proceso de reproducción transnacional de la fuerza de trabajo migrante, sino también de las condiciones estructurales de exclusión social y precarización laboral que enfrenta esta fuerza de trabajo. Como fondo salarial, las remesas reflejan también un marcado carácter de clase que da cuenta del contexto de precariedad, vulnerabilidad y exclusión social que afecta a los trabajadores migrantes y sus familias. Adicionalmente, las remesas configuran un sistema de transferencias que fluyen de trabajadores precarios y vulnerables hacia sus familiares que viven en condiciones de pobreza y contextos de marginación social. Esa condición estructural de las remesas es lo que explica en gran medida que se destinen fundamentalmente para financiar el consumo cotidiano de las familias, tal como lo hace cualquier otra forma salarial que perciben los trabajadores.

El caso de México ilustra esta situación estructural de las remesas, en cuanto a las condiciones de los hogares que las envían y a las condiciones socioeconómicas de los hogares que las perciben. Un primer dato a considerar es la condición de pobreza y vulnerabilidad que caracteriza en general a los hogares mexicanos en Estados Unidos. De acuerdo con datos de la Encuesta Continua de Población de 2018 de ese país (Buró de Censo de Estados Unidos, 2018), se estima que para ese año, 20 por ciento de los mexicanos residentes en Estados Unidos se ubicaban por debajo de la línea de pobreza, a la vez que otro 36 por ciento se situaba en 
condiciones de muy alta vulnerabilidad social, con ingresos que no superan los 15 mil dólares al año, o bien que no superan en 1.5 veces la línea de pobreza. En sí, 56 por ciento de los mexicanos residen en condiciones de alta vulnerabilidad social, pobreza y precariedad económica.

De igual modo, conforme a un módulo especial de esa misma encuesta, en 2008 se lograron medir diversas características de los hogares y migrantes que envían remesas hacia sus familias y comunidades de origen. Referente a la migración mexicana en ese país, se encontró que el ingreso anual de los hogares que enviaron remesas en 2008 no superaba los 45 mil dólares. Dichos hogares habrían enviado, en promedio, alrededor de 9 mil dólares en ese año, lo que indica que habrían remesado aproximadamente 20 por ciento de sus ingresos.

Visto desde los hogares perceptores de remesas en México, la situación de precariedad no es muy diferente. El gran volumen anual de remesas es en realidad una ilusión estadística. Los más de 33 mil millones de dólares de remesas que según el Banco de México se percibieron en 2018, se canalizaron a través de más de 100 millones de transferencias, lo que implica un promedio de 325 dólares por transferencia, aproximadamente. La situación no es muy diferente en años anteriores. De hecho de 2000 a 2017 el monto promedio por operación fluctúa entre 300 y 350 dólares. Ello hace que en el nivel de los hogares, las remesas se compongan de pequeñas transferencias diarias que sólo les permite solventar el gasto diario en consumo, alimentos y otras necesidades y servicios básicos. Incluso con las remesas, más de 38 por ciento de los hogares receptores aún viven por debajo de la línea de pobreza oficial en México y otro 20 por ciento se ubica en condición de alta vulnerabilidad, condición que enfrentan parcialmente con las remesas, de ahí el gran valor que poseen para los hogares. Entre 2014 y 2016, por ejemplo, las remesas representaron un flujo de alrededor de 30 por ciento de los ingresos monetarios de los hogares perceptores, cifra que les permitió financiar 54 por ciento del gasto en bienes y servicios básicos (alimentación, salud, educación, agua, electricidad, etcétera) (Canales y Rojas, 2018).

En síntesis, mediante las remesas se consolida un sistema global de reproducción de la fuerza de trabajo, donde los espacios de reproducción se localizan preferentemente en las economías periféricas, mientras que los momentos y espacios de trabajo en las economías centrales. La migración en sentido Sur-Norte y su correspondiente contraparte, el flujo de remesas en sentido Norte-Sur, representan la forma en que dichos espacios y momentos de la producción (trabajo) y reproducción social de la fuerza de trabajo se articulan en la economía global. 
Por ende, las remesas y la migración adquieren un claro carácter de clase. La migración corresponde a una forma que asume una fracción de la clase operaria en el capitalismo global, a la vez que las remesas que ellos envían son una forma que adopta su salario como fondo para sustentar la reproducción social de esa clase específica de trabajadores y su familia. Así, a través de la migración el capital logra disponer de fuerza de trabajo necesaria para la generación de excedentes y plusvalía, paralelamente con las remesas se asegura en parte la reproducción social de esta fuerza de trabajo. En adición, la articulación de tales espacios de producción (trabajo en países centrales) y reproducción (familias en países periféricos), constituyen una forma de abaratamiento de la fuerza de trabajo para el capital, hecho que contribuye a sustentar el proceso de acumulación a escala global.

\section{Redes sociales, transnacionalismo y clases sociales}

Si con la migración internacional las comunidades de origen se han transnacionalizado, es posible afirmar que con ello también se ha transnacionalizado el momento de la reproducción de la fuerza de trabajo migrante. En la presente era global, la reproducción de la fuerza de trabajo se desterritorializa y adopta una forma translocal, en este caso, transnacional, en la medida que articula campos y momentos situados en lugares separados por fronteras nacionales. De ese modo, en la medida que la reproducción social de la fuerza de trabajo se sustente en la migración internacional y en la conformación de comunidades transnacionales, estas mismas comunidades pasan a formar parte fundamental del proceso de globalización de la sociedad contemporánea.

Es importante aclarar que no debe confundirse el carácter transnacional de las comunidades de migrantes con su globalización. En el actual contexto de globalización, las comunidades transnacionales y la transmigración adquieren un significado especial. En no pocos casos, las redes sociales de reciprocidad, confianza y solidaridad operan como una forma de enfrentar el problema de la vulnerabilidad social y política que surge por la condición étnica y migratoria de la población, y que la ubica en una situación de minoría social. Los trabajadores migrantes, atrapados en contextos de desigualdad y precariedad generados por el proceso de globalización, articulan formas de respuestas, aunque no necesariamente de salida, a los procesos mencionados como actores dentro de sus propias comunidades. 
Dentro de ese ámbito, se puede entender el resurgimiento de formas básicas y primarias de solidaridad, confianza y reciprocidad, como las redes sociales y familiares y que dan forma y sustento a las comunidades transnacionales. La misma constitución de comunidades transnacionales abre oportunidades de acción para enfrentar la situación de vulnerabilidad por medio de las redes sociales que las sustentan. Los riesgos del traslado, los costos del asentamiento, la búsqueda de empleo, la inserción social en las comunidades de destino, la reproducción cotidiana de la familia en las comunidades de origen, entre otros aspectos, tienden a descansar sobre el sistema de redes y relaciones sociales que conforman las comunidades transnacionales, de manera que facilitan el desplazamiento y la inserción laboral del migrante. En ese sentido, el capital social les permite a los migrantes enfrentar y configurar respuestas a las condiciones de precariedad de su empleo, derivadas de la flexibilidad laboral y desregulación contractual que caracterizan los mercados laborales en la presente era.

Las comunidades transnacionales definen un campo de acción y de mediación, una estructura de opciones que el migrante laboral puede desarrollar con la finalidad de asumir y distribuir los costos de su accionar y reproducción en la globalización.

\section{4} Las redes sociales y las comunidades transnacionales tienen entonces un doble papel. Por un lado, en tanto estrategia de respuesta, es también una forma de reproducción de las condiciones de subordinación social producidas por la globalización. Por otro lado, en tanto campo de acción alternativo, las comunidades transnacionales pueden, asimismo, configurar ámbitos sociales a partir de los cuales se pudiera trascender los reducidos marcos de negociación impuestos por la globalización. ${ }^{2}$

Tradicionalmente, dichos procesos se han analizado y conceptualizado como una forma de reproducción de la misma comunidad migrante, la cual al producirse con base en la interacción entre dos ámbitos distantes y separados por fronteras nacionales, adquiere el nombre de transnacional (Levitt y De la Dehesa, 2017). En este caso se pretende dar un giro adicional al mecanismo de reproducción social de la comunidad aludido y centrar la atención en la reproducción de la fuerza de trabajo migrante.

${ }^{2}$ Sobre este punto es preciso plantear el distanciamiento respecto a ciertos autores que asumen una posición optimista y «celebratoria» respecto a la capacidad de las comunidades de migrantes para enfrentar con un hipotético éxito las condiciones de su reproducción social. El que se abra un campo de acción alternativo no asegura que ella sea exitosa. Antes bien, define un campo de confrontación, de conflictos y contradicciones, que más que determinar un resultado, define las condiciones en que se desarrolla la acción colectiva e individual frente a contextos adversos y de dominio y hegemonía de otros sujetos y clases sociales. 
Se considera que con la reproducción social de la comunidad y de las familias, no sólo se reproducen las personas así en abstracto, también, y fundamentalmente, se reproduce su posición social en un contexto particular de relaciones económicas y laborales. Si desde la demografía, la antropología o la sociología contemplamos a las redes sociales y su transnacionalidad como una estrategia de reproducción social de la población, de las familias o de la comunidad; desde la economía política y, en específico, desde la perspectiva de la reproducción del capital, observamos estos mismos mecanismos como la base social para la reproducción de la fuerza de trabajo en el actual contexto de globalización económica. ${ }^{3}$

Las redes y el capital social de los migrantes son el mecanismo de reproducción de la migración como proceso social; pero no se trata de la reproducción de una migración en general, sino de migrantes laborales que se insertan en actividades productivas para el capital en los países de destino y participen de ese modo de las estructuras de diferenciación social, es decir, de la estructura de clases sociales en el nivel de la sociedad global. En definitiva, la forma que asume la reproducción de una clase social en el capitalismo global: los trabajadores migrantes y, por tanto, la forma que asume de igual modo la reproducción de la estructura de clases en las sociedades avanzadas.

\section{Conclusiones. Trabajo global, trabajadores locales}

Con base en el funcionamiento de la economía, la migración representa un mecanismo demográfico y social, que contribuye al menos de dos modos a la reproducción del sistema económico y, por ese medio, a la acumulación de capital a escala global: a) Aporta el volumen de fuerza de trabajo necesaria para sustentar la actividad económica y productiva en los países de destino, de manera que contribuye a solventar la insuficiencia demográfica generada en esos países, derivado de la combinación de los procesos de envejecimiento de su población

${ }^{3}$ Por lo mismo, no se trata de procesos diferentes, nuevos, o emergentes, sino de lecturas diferentes de un mismo proceso. De hecho, nuestra lectura intenta precisamente, integrar todas estas visiones que se han elaborado desde diversos campos disciplinarios y de investigación, para arribar a un modelo más amplio y comprehensivo de la migración internacional. Lo nuevo de esta propuesta no está en que se apunte a procesos emergentes o novedosos, sino en la forma cómo se leen o se interpretan los mismos procesos que ya han sido ampliamente documentados por los más diversos autores. 
y avance de la segunda transición demográfica. b) Colabora con mano de obra que simultáneamente exhibe bajos costos de reproducción social, se inserta en el mercado laboral en un contexto de alta precariedad, inestabilidad y flexibilidad laboral. Se trata de trabajadores cuya condición de migrante (e indocumentado la mayor de las veces) los ubica en situación de alta vulnerabilidad social.

De modo complementario, dichas contribuciones económicas y laborales de la migración se sustentan en la conformación de redes sociales, que a partir de un sistema de relaciones de solidaridad, reciprocidad y apoyo mutuo permiten el desplazamiento cotidiano de trabajadores migrantes desde las comunidades de origen a los mercados laborales en las sociedades avanzadas. Mediante las redes se reducen los costos y riesgos del desplazamiento, al mismo tiempo que posibilita la obtención de empleos y la integración a una comunidad de acogida. En adición, por medio de estas mismas redes sociales fluyen recursos materiales, monetarios y simbólicos que propician la reproducción de las familias y los migrantes en sus lugares de origen. En este caso destaca el flujo de remesas por los altos montos que involucran y por su importancia y significado social, como fondo salarial que da sustento a la reproducción de los migrantes y sus familias.

Todo ello, conforma un sistema global de reproducción de la economía, donde la migración contribuye en un doble sentido: a) Como fuerza de trabajo, esto es, la mercancía que el trabajador vende al capitalista, coadyuva a la reproducción y acumulación del capital. Se trata de su aporte al momento productivo de la reproducción del sistema económico global.b) A través de las redes y capital social que los migrantes ponen en movimiento al desplazarse, se configura una forma de reproducción de esa misma fuerza de trabajo de los migrantes. Se refiere al aporte de la migración al momento de la etapa reproductiva del sistema económico global.

La visión conjunta de ambos momentos facilita la comprensión concerniente a que no se trata de la reproducción de fuerza de trabajo para el capital, pura y simplemente, sino de trabajadores migrantes vulnerables y desprotegidos, susceptibles de insertarse en ocupaciones altamente flexibles, inestables y con altos niveles de precariedad laboral.

Igualmente, la migración contribuye a reducir los costos de reproducción de la fuerza de trabajo para el capital. En concreto, mediante las mismas redes sociales que en un sentido sustentan la migración, en sentido opuesto contribuyen a traspasar a las familias y comunidades de origen parte del costo de reproducción 
de dicha fuerza de trabajo. De ese modo, el salario y las remuneraciones que perciben los migrantes en los lugares de destino, ya no tienen que cubrir necesariamente todo el costo de reproducción de la fuerza de trabajo, pues parte de ese costo ha sido trasladado a las familias en sus lugares de origen, y es cubierto con otros ingresos y recursos de la familia. En otras palabras, tanto la reproducción cotidiana como intergeneracional de la fuerza de trabajo descansa, en gran medida, en recursos familiares y comunitarios, así como en los gastos y subsidios que al respecto hacen los estados de los países de origen (educación, salud, transporte, entre otros).

Se plantea entonces una situación paradójica con relación a la migración y a la globalización. Aunque los migrantes casi nunca aparecen como uno de los actores que concentre los reflectores de la globalización, su trabajo sí forma parte directa de la globalización del capital, en la medida que constituye, como hemos visto, un elemento sustancial en la producción, crecimiento y la misma dinámica económica de los países desarrollados. Como trabajo, los migrantes participan directamente de la globalización y colaboran a la reproducción y acumulación del capital a escala global. Como trabajo concreto (en su valor de uso, productor de mercancías) se materializa en cada bien y servicio que se comercializa en todo el mundo. Como trabajo abstracto (producción de valor, tiempo de trabajo) se objetiva en el valor de cada mercancía que circula día a día en los diversos mercados globales alrededor del mundo.

Sin embargo, como trabajadores, los migrantes son continua y permanentemente relegados a los confines de la globalización, alejados del glamour que ella encierra y siempre a la sombra de su trabajo; siempre como meros actores de reparto, simples extras de una gran producción global. Como trabajadores, su globalización queda restringida a la desterritorialización de los espacios de su reproducción como fuerza de trabajo, esto es, a los espacios restringidos de sus comunidades, que a pesar de que adoptan una forma translocal y transnacional se encuentran muy distantes de adoptar una forma global. Como trabajadores, como personas, como fuerza de trabajo, su reproducción se podrá haber transnacionalizado, pero en ningún caso se habría mundializado.

Así, la migración configura un mecanismo que articula dos momentos de la globalización económica: en tanto forma trabajo, coadyuva a la globalización desde arriba, es decir, a la globalización del capital y sus actores y representantes. Como forma fuerza de trabajo, es parte de una globalización desde abajo, esto es, de desterritorialización de la reproducción del trabajador y su fuerza de trabajo 
que requiere el capital global. La problemática de los migrantes, es que a ellos sólo les pertenece su fuerza de trabajo, no su trabajo; de ahí que aunque su trabajo sea parte de la gran globalización del capital, para que ello ocurra, previamente deberán enajenar su fuerza de trabajo vendiéndosela al capital, quien precisamente no hace sino extraer el trabajo allí contenido (valor) y acumularlo en su forma global, al trabajador lo retorna a sus formas subordinadas y muy locales de globalización.

Mientras su trabajo materializado en los más diversos productos, artefactos, bienes y mercancías, circulan por todo el mundo, traspasando fronteras, formando parte de la gran farándula de la globalización, ellos los trabajadores, los que desde abajo son los verdaderos artífices de este proceso, quedan relegados a desplazamientos translocales, a espacios de reproducción localmente situados y restringidos, incluso expuestos a diversas formas de segregación territorial y discriminación social y étnico-racial. Sus barrios podrán ser una característica de las ciudades globales, pero no dejan de ser barrios locales, guetos dentro de una globalización que los excluye en su reproducción. He aquí, una de las grandes paradojas de la migración: la globalización del trabajo y la producción, esto es, de la reproducción del capital, supone sin embargo, circunscribir y mantener en ámbitos locales la reproducción de la fuerza de trabajo. Arribamos así, a una nueva acepción para el término glocalización, que se agrega a las de Bauman (1998) y Robertson (1992): globalización y mundialización del capital y su acumulación, como contracara de la localización de la reproducción de la fuerza de trabajo que sustenta y reproduce a aquel.

En ese sentido, es posible entender el doble carácter de la migración contemporánea: a) Como provisión de fuerza de trabajo para el capital es una estrategia del capitalismo a fin de obtener el trabajo indispensable para sostener su reproducción ampliada en el marco de su propia globalización. b) Como un proceso social en redes familiares y capital social es una estrategia de reproducción de los trabajadores (fuerza de trabajo) que aunque adopta una forma transnacional y translocal sigue siendo localizada y confinada a espacios locales y excluidos del espectáculo de la globalización del capital y la nueva economía.

Con fundamento en lo anterior, se afirma que en el marco de la globalización, el análisis de la migración internacional debe apoyarse obligatoriamente en la problematización de las estructuras de desigualdad y diferenciación social que surgen de la propia globalización. Se trata, no obstante, de una cuestión que no siempre ha sido recuperada en el debate sobre las migraciones contemporáneas. 
Desde los enfoques neoclásicos, por ejemplo, el problema de la desigualdad y la migración se enfrenta como una cuestión coyuntural, en la medida que la misma migración representa un mecanismo para alcanzar los necesarios equilibrios, tanto en cuanto a salarios y condiciones de vida de la población como a las asimetrías en las productividades y niveles de desarrollo interregionales.

Por su parte, en los enfoques estructuralistas clásicos el análisis tendió a considerar la desigualdad social como un remanente o rezago social. Por ejemplo, el enfoque histórico-estructural si bien ponía el acento en la desigualdad social, lo conceptuaba en términos de la exclusión y marginación social de que eran objeto determinados sectores de la población (migrantes, jóvenes, mujeres, campesinos, sector informal). Eran trabajadores supernumerarios constantemente expulsados del mercado de trabajo, que conformaba un ejército de reserva, una constante sobreoferta de mano de obra. En ese sentido, el marco de vulnerabilidad y precariedad de tales trabajadores supernumerarios, residía en su exclusión o marginación del mercado laboral (Nun, 1969).

Justamente desde esta perspectiva, sin embargo, se argumenta que con la globalización se configuran nuevas formas de desigualdad social que no se corresponden ni con las formas tradicionales de marginación social, ni menos aún con la persistencia de estructuras sociales tradicionales o premodernas. En la globalización, la pobreza y la precariedad de los trabajadores, en específico de los migrantes, no es resultado de su exclusión del mercado de trabajo (desempleo, ejército industrial de reserva), por el contrario, es consecuencia de la forma en que ellos son incluidos e integrados en el mundo laboral como trabajadores migrantes. No se trata ya de un empobrecimiento por marginación social y económica, esto es, empobrecimiento por haber sido excluidos, expulsados del mercado de trabajo, de la economía formal, en todo caso se trata de trabajadores socialmente vulnerables, pero plenamente insertos en una economía dinámica y global.

En el actual contexto de desregulación económica y flexibilidad laboral es la propia modernización y globalización la que genera y reproduce sus propias formas de pobreza, es decir, de una pobreza moderna y global. Según Ulrich Beck (1998), en la sociedad global el capitalismo ha roto con las bases de la sociedad del trabajo y el estado de bienestar, en un horizonte en el cual el crecimiento de la economía ya no asegura ni la supresión del desempleo, ni el mejoramiento de las condiciones de vida y trabajo de la población.

Con relación a los migrantes, ellos no están expuestos a una situación de exclusión social propiamente tal, al menos no en su sentido tradicional. Antes 
bien, están expuestos a condiciones de vulnerabilidad y de desigualdad social. De cualquier manera, si hubiera de usarse el término exclusión, éste haría referencia a formas de inclusión fragmentada, vulnerable y precaria, que a una expulsión o marginación de la economía y la sociedad. En estricto sentido, se trata de un proceso contradictorio que es simultáneamente de inclusión y exclusión social. Es una inclusión desde abajo, parcial y contradictoria, sustentada en tiempos y espacios de exclusión. En la sociedad global la condición de minoría social (condición migratoria, en nuestro caso) deja de ser el riesgo de una posible exclusión económica, hasta convertirse en la condición necesaria para su inclusión fragmentada, parcial y precaria. Así, la reproducción del sistema económico global (y por tanto, el crecimiento económico y acumulación de capital) descansa en definitiva, en la reproducción ad infinitum de dicha condición de desigualdad social, que es también la base para la sobreexplotación de los trabajadores migrantes.

Es interesante constatar que ésta es la base económica del malestar con las migraciones que prevalece en las economías centrales. En cierto modo, es un malestar con una de las bases de sustentación de la economía política del capitalismo global, es decir, la necesidad de acumulación con base en la explotación del trabajo migrante. Semejante situación parece definir un dilema económico que enfrenta la producción y acumulación de capital: requiere la provisión continua y recurrente de mano de obra extranjera, de fuerza de trabajo de los migrantes. El problema es que ese trabajo viene en formato de trabajadores y personas migrantes, de extranjeros, con derechos y necesidades, formas y estilos de vida propios. Su malestar entonces es contra esa insoportable incapacidad de su propia economía de generar la fuerza de trabajo indispensable para reproducir y acumular sus capitales, su capitalización, es un malestar con la dependencia que presenta su reproducción como economías centrales y hegemónicas con respecto al trabajo y fuerza de trabajo proveniente de economías subordinadas y periféricas, y que se pone disponible bajo la forma de migraciones.

En anteriores patrones de acumulación de capital, el trabajo y la fuerza de trabajo provenían de dos fuentes: de la propia capacidad de las economías centrales de generarlo a través de su demografía, y de la explotación de trabajo ajeno, pero en lugares distantes y geográficamente periféricos. Hoy, en cambio, la globalización de la economía ha implicado internalizar ese trabajo ajeno y extraño dentro de los límites territoriales de sus economías y de sus espacios de vida, producción y consumo. 
La globalización de la economía, con todos los beneficios y privilegios que conlleva para las economías centrales y para sus poblaciones y clases sociales, va de la mano de la globalización del trabajo y la fuerza de trabajo. Si en la globalización el capital ya no está atado a fronteras nacionales ni a espacios locales para su reproducción y acumulación, tampoco el trabajo y la explotación de la fuerza de trabajo se encuentran limitadas por esas fronteras nacionales y territoriales. En la globalización, la economía política de la reproducción y acumulación del capital ha roto las fronteras nacionales que la restringían y territorializaban en la sociedad moderna e industrial.

Pero el problema es que esta disolución de fronteras no sólo opera para el capital, sino también para la fuerza de trabajo, además de que permite expandir e intensificar la producción capitalista más allá de las fronteras nacionales, opera en un sentido inverso, de manera que expande e intensifica la movilidad y el asentamiento de la fuerza de trabajo más allá de las fronteras nacionales. La misma necesidad del capital de las economías centrales de proveerse de mano de obra periférica, es lo que plantea una situación de dependencia frente a esa fuerza de trabajo que bajo la forma de migraciones internacionales se moviliza y desplaza desde las economías periféricas hacia las centrales. Dicha necesidad y dependencia de fuerza de trabajo ajena y extraña es lo que configura la economía política de este malestar con las migraciones que prevalece y se expande en las sociedades avanzadas. Es un malestar frente a la nueva forma que adopta la estructura de clases en sus sociedades, donde la migración no sólo constituye un modo de provisión de mano de obra barata, de igual modo, la configuración de un nuevo estamento social, de una nueva clase de trabajadores que por esa razón, plantea nuevos modos de contradicción capital-trabajo, nuevas formas de conflicto y contradicciones sociales, culturales y demográficas.

\section{Referencias}

Amin, Ash (2000), Post-Fordism, a reader, Oxford, Blacwell Publisher Ltd. Balibar, Étienne (2004), «Acerca de los conceptos fundamentales del materialismo histórico", en Louis Althusser y Étienne Balibar, Para leer el capital, México, Siglo XXI, pp. 212-335. 
Banco Mundial (2019a), Annual remittances data, Washington, DC, en https://www. worldbank.org/en/topic/migrationremittancesdiasporaissues/brief/migration -remittances-data

(2019b), «Indicadores», en http://datos.bancomundial.org/indicador

Bauman, Zygmunt (1998), «On glocalization: or globalization for some, localization for some others", Thesis Eleven (54).

Beck, Ulrich (1998), Qué es la globalización. Falacias del globalismo, respuestas a la globalización, México, Paidós.

Bell, Daniel (1973), The coming of post-industrial society. A venture in social forecasting, New York, Basic Books.

Buró del Censo de Estados Unidos (marzo de 2018), Current Population Survey, ASEC.

Canales, Alejandro I. (2018), "Global and regional political economy of migration», en Ernesto Vivares (ed.), Regionalism, development and the post-commodities boom in South America, United States, Palgrave Macmillan.

(2017), «Migración y trabajo en Estados Unidos. Polarización ocupacional y racialización de la desigualdad social en la postcrisis», REMHU, Revista Interdisciplinar da Mobilidade Humana, 25(49).

102

Canales, Alejandro I. y Martha Luz Rojas (2018), Panorama de la migración internacional en México y Centroamérica, Santiago, CELADE/División de Población de CEPAL/OIM.

Castells, Manuel (1998), La era de la información. Economía, sociedad y cultura. Volumen $1 \mathrm{La}$ sociedad red, Madrid, Alianza Editorial.

Castillo, Dídimo y Adrián Sotelo (2013), «Latin America: outsourcing and the new labor precariousness», Latin American Perspectives, 40(5).

Castro, Antonio y Carlos F. Lessa (1991[1969]), Introducción a la economía: un enfoque estructuralista, México, Siglo XXI.

Cypher, James y Raúl Delgado Wise (2010), Mexico's economic dilemma: the developmental failure of neoliberalism, United States of America, Rowman \& Littlefield Publisher Inc.

David, Paul A. y Dominique Foray (2002), «Una introducción a la economía y sociedad del saber», Revista Internacional de Ciencias Sociales (171), en http://www.unesco.org/ new/fileadmin/MULTimEDIA/HO/SHS/pdf/171-fulltext171spa.pdf

De Haas, Hein (2007), Remittances, migration and social development. A conceptual review of the literature, United Nations, Research Institute for Social Development, Social Policy and Development Programme Paper Number 34.

European Comission (s/f), "Eurostat», en http://ec.europa.eu/eurostat/data/database 
Hirst, Paul y Jonathan Zeitlin (1991), «Flexible specialization versus post-fordism: theory, evidence and policy implications», Economy and Society, 20(1), pp. 5-9.

Koch, Max (2017), Roads to post-fordism: labour markets and social structures in Europe, Reino Unido, Routledge.

Lash, Scott y John Urry (1998), Economías de signos y espacios. Sobre el capitalismo de la postorganización, Buenos Aires, Amorrortu.

Levitt, Peggy y Rafael de la Dehesa (2017), "Rethinking stransnational migration and the re-definition of the states or what to do about (semi-) permanent impermanence», Ethnic and Racial Studies, 40(9), pp. 1520-1526.

Marx, Karl (1972[1867]), El capital. Crítica de la economía política. Tomo I, México, Fondo de Cultura Económica.

Marx, Karl (1971), Critique of political economy (Grundrisse), London, Lawrence and Wishart.

Massey, Douglas S. (1990), «Social structure, household strategies and cumulative causation of migration", Population Index, 56(1), pp. 3-26.

Mendieta, Eduardo (2007), Global fragments. Globalizations, Latinamericanisms and critical theory, Albani, NY, State University of New York Press.

Nun, José (1969), «Superpoblación relativa, ejercito industrial de reserva y masa marginal», Revista Latinoamericana de Sociología, V(2).

Polanyi, Karl (2017[1944]), La gran transformación. Los orígenes politicos y económicos de nuestro tiempo, México, Fondo de Cultura Económica.

Robertson, Roland (1992), Globalization. Social theory and global culture, London, UK, SAGE Publications.

Samuelson, Paul y William Nordhaus (2005), Economía, México, Mc Graw Hill.

Sassen, Saskia (1998), Globalization and its discontents, New York, The New Press.

Stiglitz, Joseph E. (2002), Globalization and its discontents, New York, W.W. Norton \& Co.

U.S. Bureau of Economic Analysis (2018), «Real value added by industry», en http:// bea.gov/industry/gdpbyind-data 